\title{
Key sources of operational inefficiency in the pharmaceutical supply chain
}

\author{
Marina Papalexi and David Bamford \\ Department of Operations, Technology, Events and Hospitality Management, Faculty of Business and Law Business School, \\ Manchester Metropolitan University, Manchester, UK, and \\ Liz Breen \\ School of Pharmacy and Medical Sciences, University of Bradford, Bradford, UK
}

\begin{abstract}
Purpose - This study aims to explore the downstream pharmaceutical supply chain (PSC) and provides insight to the delivery process of medicines and associated operational inefficiencies.

Design/methodology/approach - An exploratory, qualitative approach was adopted to examine PSC inefficiency within two European contexts, namely, the UK and Greece. Data was gathered through interviews and a thematic analysis conducted to analyse the data and identify challenges faced by both supply chains(SCs).

Findings - The medicines delivery system needs to be enhanced in terms of quality, visibility, speed and cost to perform effectively. The findings demonstrated that although the healthcare SCs in the two European contexts have different operational structures, the results are in concordance with each other. Financial, communication, waste and complexity issues were the major concerns.

Research limitations/implications - To the knowledge this is the first study to examine aspects of the medicines SC via a cross-case analysis in the UK and Greece and extends the body of knowledge. A broader sample of responses is warranted to further validate these findings.

Practical implications - The study outputs can inform pharmacies' strategic to instigate targeted improvement interventions. The implications of which may be extrapolated further to other European healthcare organisations.

Originality/value - This research contributes to the academic literature by adding further theoretical insights to SC strategy development, especially those that have been characterised as highly complex. The study identifies four key areas of intervention needed within this SC (in both countries) to promote higher level efficiencies and effectiveness.
\end{abstract}

Keywords Efficiency, Healthcare service, Improvement, SCM performance, Pharmaceutical supply chain, Improvement approaches, Inefficiencies, Healthcare

Paper type Research paper

\section{Introduction}

Healthcare organisations are responsible for promoting public health through improving the individual patient care experience in terms of quality, access and reliability. The efficient functioning of a healthcare system requires investments and constant improvement to be able to meet the increased demand for high quality services (Chassin, 2013). However, considering that healthcare costs, globally, are growing rapidly, there has been extensive pressure on healthcare organisations, especially on those where related expenditures represent a substantial proportion of the gross domestic product (GDP), to minimise their expenses without sacrificing service quality (Ferreira et al., 2018; Narayanamurthy et al., 2018); it is estimated that total worldwide drug expenditure in 2020 will be over US $\$ 1.4$ tn (Statista, 2018). In addition, the perceived high level of wastage associated with pharmaceuticals significantly increases this cost (Papalexi et al., 2015; Cherrett et al., 2012); US $\$ 13.3$ bn is the estimated global

The current issue and full text archive of this journal is available on Emerald Insight at: https://www.emerald.com/insight/1359-8546.htm

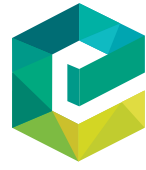

Supply Chain Management: An International Journal Emerald Publishing Limited [ISSN 1359-8546] [DOI 10.1108/SCM-02-2019-0076] medical waste management market in 2020 (Medical Waste Management Market, 2018). Literature indicates that the implementation of effective supply chain (SC) practices offers solutions to healthcare organisations and assists in facing this challenge (Pohjosenperä et al., 2018; Bhakoo et al., 2012).

There is, therefore, a need for optimising the pharmaceutical supply chain (PSC) to achieve cost-saving, waste elimination and high-quality services. Uthayakumar and Priyan (2013, p. 52) defined the PSC as:

[...] the integration of all activities associated with the flow and transformation of drugs from raw materials through to the end-user, as well as associated information flows, through improved supply chain relationships to achieve a sustainable competitive advantage

(C) Marina Papalexi, David Bamford and Liz Breen. Published by Emerald Publishing Limited. This article is published under the Creative Commons Attribution (CC BY 4.0) licence. Anyone may reproduce, distribute, translate andcreate derivative works of this article (for both commercial and non-commercial purposes), subject tofull attribution to the original publication and authors. The full terms of this licence may be seen at http://creativecommons.org/licences/by/4.0/legalcode

Received 20 February 2019

Revised 20 June 2019

23 September 2019

26 September 2019

Accepted 30 September 2019 
There have been a number of reported documents and articles suggesting initiatives that can potentially improve the PSC. Reviewing the academic literature, scholars investigating the PSC found that certain benefits can be claimed, including effective inventory control (Bam et al., 2017; Pereira et al., 2014), improved information reliability (Chowdhury et al., 2016), firm innovativeness (Papalexi et al., 2015; Gölgeci and Ponomarov, 2015), organisational performance (Birkie et al., 2017), reduction of pharmaceutical waste and increased quality of healthcare services, (Pohjosenperä et al., 2018; Volland et al., 2017; Breen and Xie, 2015). Similarly, to the treatise within the academic literature, from a practical perspective, healthcare institutes such as the Department of Health (UK) and the national organisation for medicines (Greece) have outlined a series of guidelines aiming to determine how best practices can be adopted to enhance the delivery process (Department of Health (DoH), 2014; NOfM, 2016). However, healthcare organisations are facing difficulties in undertaking improvement initiatives, which explains why they have limited experience in adopting them, when compared with the industrial and retail sectors (Narayanamurthy et al., 2018). Brown et al. (2013) explained that the healthcare sector is different because healthcare services impact upon society and, as a result, the possibility of failure is not acceptable. Focussing on the PSC, the actual delivery process of medicines is lengthy and has been characterised as a more complex system than exists in other industries (Birkie et al., 2017; Mustaffa and Potter, 2009).

The literature has indicated many strategies for improving the performance of the PSC, but there is a noticeable gap in research on the comparison of the strategies applied within different geographical contexts and different domain focus of the PSC. To address this gap in the current academic research (Alvesson and Gabriel, 2013), this research aims to provide additional theoretical and practical insights (Baraldi et al., 2014) to the operational inefficiencies associated with the PSC used in two European countries, namely, the UK and Greece. It evaluates the challenges that pharmacies face when distributing medicines within this supply focussing specifically on impediments to effective delivery to customers and patients. An exploratory, qualitative approach was adopted and the following research question $(R Q)$ was developed to focus the study methodology:

$R Q 1$. What are the challenges associated with the medicines delivery process within the downstream domain of the PSC in the UK and Greece?

This $R Q$ yielded the following two sub-questions, namely:

Q1. What are the common operational issues observed within the downstream domain of the PSCs, which impact on medicines delivery?

Q2. What are the region-dependent operational issues observed within the downstream domain of the PSCs, which impact on medicines delivery?

Firstly, this paper investigates the PSC downstream domain to identify the factors that impact upon the system's underperformance, which is a critical step for developing and improving the distribution of the finished products to customers (patients). The research focus will contribute to the lack of focus on the PSC downstream network in the existing literature, as reported by Narayana et al. (2014) and Bam et al. (2017) and extend the work of previous studies e.g. waste management (Xie and Breen, 2014); change management in healthcare (Burnes and Jackson, 2011); and inventory management (Bhakoo et al., 2012). According to Nicholson et al.'s (2018, p. 217) contribution conceptual framework, an incremental contribution is reached, which is measured against existing knowledge and develop further what is currently known. Secondly, there is a need to understand the medicines delivery strategies implemented in different geographical contexts, which might reinforce or contradict each other. Specifically, this research explores the downstream domain of the PSC applied within two diverse European countries, the UK and Greece to identify the common and region-dependent issues observed within the medicines delivery process; the countries selection criteria are presented in Section 3.1. This study has involved an interdisciplinary approach to ensure the accuracy and validity of design, analysis and outputs. While it has adopted a single lens of analysis [that of operations/supply chain management (SCM)], it has consulted with and involved researchers from both schools of pharmacy and schools of management (Zacharia et al., 2014). This interdisciplinary approach is characterised as a revelatory contribution by Nicholson et al. (2018). Indeed, Cheng et al. (2009) suggested that interdisciplinary research generates fruitful insight through integrating and combining concepts in a theoretical and practical contribution. To our best knowledge this aspect of the medicines SC via a cross-case analysis is underrepresented in the literature. The remainder of this paper is organised as follows. In Section 2, the relevant literature is presented arguing that complex systems such as the PSC, require wellestablished strategies to be managed effectively. Section 3 outlines the research method adopted to explore the subject under investigation. Subsequently, the findings section (Section 4) details the root-cause problems that are associated with the weak performances in both countries, which is a prerequisite for optimising the downstream domain of the PSC. This followed by Section 5, which discusses the contribution of this research; additional theoretical and practical insights are provided to SC strategy development, especially those that have been characterised as highly complex. Finally, conclusions and limitations of the study are, thereafter, presented in Section 6.

\section{Literature review}

Scholars have developed comprehensive insights into the concept of operational efficiency, providing a wealth of different definitions. It is agreed that operational efficiency is mainly connected to "doing the things right" (Førsund, 2017, p. 93). Operational efficiency can be measured by assessing the outcomes of the operation against the five key performance indicators, namely, quality, flexibility, speed (delivery), dependability and cost (Birkie et al., 2017). Efficiency measurement is dependent on the environmental context (Bamford et al., 2015). Focussing on the production of healthcare services, there is a need for improving healthcare efficiency with respect to the quality of service (quality), patient safety and satisfaction (flexibility, speed and dependability) and the cost of care (cost) (Guerrini et al., 2018). The increased 
pressure on healthcare organisations to reduce their pharmaceutical spending converts this need into an urgent one (Al-Balushi et al., 2014). Hoping to overcome the limitations of a function-based organisation, many healthcare organisations have adopted various improvement approaches (Bam et al., 2017). However, these approaches remain patchy and methodologically limited (Narayanamurthy et al., 2018; Bamford et al., 2015). Based on a thorough critical review of the extant literature in this area, a number of key issues that impact upon this underperformance have been identified and are presented in Table 1 .

Although the PSC aims to meet customer demand effectively, which means patients should be able to access pharmaceutical products with ease, it is characterised as a complex enterprise because it has to deal with conflicting objectives and numerous intractable constraints (Birkie et al., 2017; Bam et al., 2017). A number of researchers have examined the PSC, concluding that there are several factors contributing to its inefficiency (Xie and Breen, 2012, 2014; Bhakoo et al., 2012). Table 2 summarises those factors, which are discussed in more detail below.
The inefficiency of medicine logistics is increased because of the involvement of numerous stakeholders within the PSC such as suppliers, pharmacists, physicians and management and clinical staff (de Vries and Huijsman, 2011). They have different roles and responsibilities within the PSC and often act as independent parties, without sharing the information required for producing healthcare services; weak information flow has been reported between the physicians and the pharmacy departments (Bhakoo et al., 2012). In addition, the fact that physicians act as the key decision-makers regarding

Table 2 Factors of PSC inefficiency

\begin{tabular}{ll}
\hline 1 & Significant number of stakeholders \\
2 & Limited understanding of OM and SCM \\
3 & The institutional and regulatory pressures \\
4 & Long development cycles \\
$\mathbf{5}$ & Difficulties in predicting the exact demand for medicines \\
6 & Difficulties in predicting the patient mix \\
7 & The particular characteristics of medicines \\
\hline
\end{tabular}

Table 1 Key issues that impact upon healthcare underperformance

\begin{tabular}{|c|c|}
\hline Key issues & Summary of literature \\
\hline Fragmented & - Centralised organisations (Narayanamurthy et al., 2018) \\
\hline Centralised environment & $\begin{array}{l}\text { - Laws, regulations and a disconnection between evidence and practice likely influence the adoption } \\
\text { and diffusion of improvement initiatives or delay them (Bamford et al., 2015; Chen et al., 2019) } \\
\text { - Fragmentation in commissioning and procurement practices (Radnor et al., 2012; Ding, 2018) } \\
\text { - Lack of interaction between industry and the public sector (Narayanamurthy et al., 2018) } \\
\text { - Sub-optional use of guidance (Liddell et al., 2008) }\end{array}$ \\
\hline
\end{tabular}

Cultural inertia

High cost of change

Awareness of improvement approaches

Complexity of the healthcare sector
- Healthcare personnel are rather sceptical of adopting any improvement approaches; changes are threats (Burnes and Jackson, 2011)

- Difficulties in changing their practices, core strengths or culture due to fear of failure or fear of the unknown (Brown et al., 2013)

- Suffering from improvement fatigue due to some elements such as the constant treadmill of government bodies changing, which influences the operations of such large organisations (Narayanamurthy et al., 2018)

- The presence of financial constraints significantly minimises the likelihood that organisations will implement improvement initiatives (D’Este et al., 2012; Guerrini et al., 2018)

- Limited knowledge of improvement approaches; there is a shortage of expertise and methods (Greenhalgh et al., 2012)

- The lack of experience might lead to adoption of incorrect methods or the sub-optional use of the existing guidance (Bhakoo et al., 2012)

- Healthcare SCs has been chartacterised as more complex compared to SCs in other industries (Liddell et al., 2008; Papalexi et al., 2015) because of the impact on patient's health requiring an adequate and accurate medical supply (Mustaffa and Potter, 2009)

- The healthcare context sensitivity is the main factor that generates the complexity of the system (Kannampallil et al., 2011; Bam et al., 2017)

- Unpredictable healthcare complex system, including a number of diverse elements, whose relationships are not linear (Wilson and Holt, 2001; Zahiri et al., 2018)

- The high complexity of the system is influenced by the specific products and services delivered by healthcare organisations and the diversity of people working within this sector, their roles and actions (Greenhalgh et al., 2012) 
the procurement of prescription medicines without having possessed an extensive knowledge of operations management $(\mathrm{OM})$ and SCM practices and techniques increases the system's underperformance (Bhakoo et al., 2012). Breen and Xie (2015) focussed on the role of pharmacists by exploring their critical management skills needed to perform effectively. Davies and Edwards (2013) highlighted that the continuous growth of the pharmacy sector (and the extended role of pharmacists (Greenwood et al., 2019)) requires more qualified pharmacists, without taking into account the lack of management modules during their degree. SCM skills are required when pharmacists are looking to improve the service quality (Uthayakumar and Priyan, 2013).

Institutional and regulatory pressures, which cause problems in determining accurate sales forecasts along with long developmental cycles of pharmaceutical products cause difficulties in applying supply chain strategies (SCS) (Bhakoo et al., 2012). There is difficulty in predicting the exact demand for medicines, partially due to the lack of standard nomenclature and partially because of the fact that medicines are stored in several areas of a healthcare organisation (Mustaffa and Potter, 2009). Similarly, it is challenging to predict the patient mix, understanding their needs and ultimately their supply consumption (Scheller and Smeltzer, 2006), specifically in emergency interventions. This unpredictable demand is one of the elements that force healthcare organisations to carry high levels of safety stock, avoiding uncertainties such as daily demand fluctuations and supply bottlenecks (Bhakoo et al., 2012). These practices could increase the level of waste observed within the PSC, which means that more expired or unwanted medication would have to be disposed of, raising the threat to the environment and human health (Wang et al., 2015). Medicines are expensive products that can be converted into dangerous or useless products for consumers due to their short expiration dates (Cherrett et al., 2012).

A main problem, therefore, facing this sector is process inefficiency related to pharmaceutical distribution. The current process inefficiency is caused by the use of basic but robust logistics and planning systems for pharmaceutical stock control; research suggests that existing systems use only simplistic push logistics (Jamali et al., 2010;). It is believed that standard logistics strategy models that have been useful in guiding managerial policy in other distribution industries are not easily applied to the PSC (Papalexi et al., 2015) due to the number of consumption points, the role and number of intermediaries and the long lead times and highly unpredictable nature of bio-pharma manufacturing, which have created a web of contingencies, interdependencies and uncertainties (Bhakoo et al., 2012). Figure 1 illustrates the

Figure 1 A conceptual model of the PSC upstream, central and downstream domains

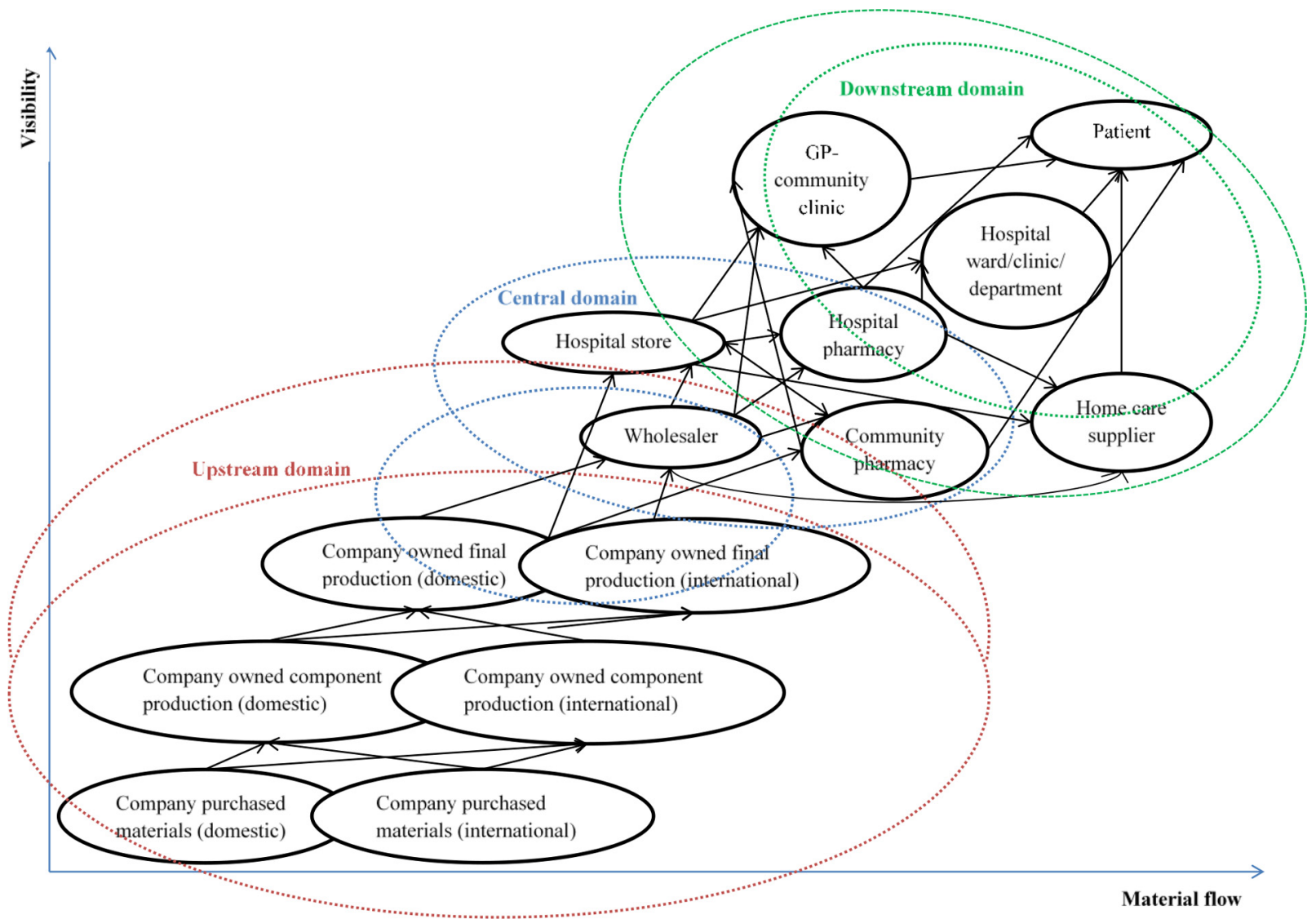

Note: cycles present the different distribution lines of each domain

Source: Papalexi, (2017) 
structure of this complex SC including the PSC upstream, central and downstream domains where different groups of stakeholders are involved.

As Figure 1 illustrates, the PSC is not linear and there are many different distribution lines. For example, stakeholders involved within the upstream domain of the PSC could be either only pharmaceutical companies that produce the products or this domain could also include the distributor/ wholesaler. The authors believe that the figure serves a useful purpose in demonstrating the complexity of the actual situation. Literature indicates that there is a low and fragmented focus on the PSC in research (Narayana et al., 2014), which is presented in Figure 1. Scholars tend to concentrate on the upstream business processes, revealing an emerging interest in exploring the interactions between pharmaceutical manufacturing and the R\&D-specific biotechnology industry (Sen et al., 2013). This study will contribute to the existing lack of focus on the PSC downstream domain as it investigates the pharmaceutical delivery practices taking place within the UK and Greece.

The above factors impact upon the medicines logistics and prevent any improvement initiatives. Although, there is a wealth of research that investigates the inefficiency of medicine logistics (Bhakoo et al., 2012; Xie and Breen, 2014), the aim of this research is to extend the existing literature by investigating the PSC downstream domain in diverse European countries, UK and Greece. This will identify factors that impact on system underperformance (in service delivery) applied in both hospitals and community pharmacies. This study raises awareness of these factors for healthcare organisations to avoid them or opt to convert them to their advantage.

Figure 2 presents the key themes emerged from the literature review section, framed against the input-transformation-output operational model. This model considers the healthcare organisation as a production operation area that needs to be improved. This could be achieved by optimising the PSC though implementing improvement initiatives. However, as Figure 2 illustrates, a number of elements associated with the PSC in conjunction with particular aspects of improvement approaches influence the implementation of such interventions and as a result the system's effectiveness.

\section{Research methodology}

\subsection{Research context}

The two countries involved in this research were, at the time of this study, members of the European Union (EU); as a result, both countries are subject to a large body of legislation that has been developed and supported by the 31 European Economic Area member states, the European Commission and the European Medicines Agency (EMA, 2014). These regulations are intended to ensure the quality, safety and efficacy of pharmaceutical products and promote the good functioning of the internal market (EC, 2015). Although the PSC in the UK and Greece operate under the same general regulations, there are some significant differences between them. Table 3 summarises the key figures for the UK and Greece.

Figure 2 Key issues related to the PSC inefficiency

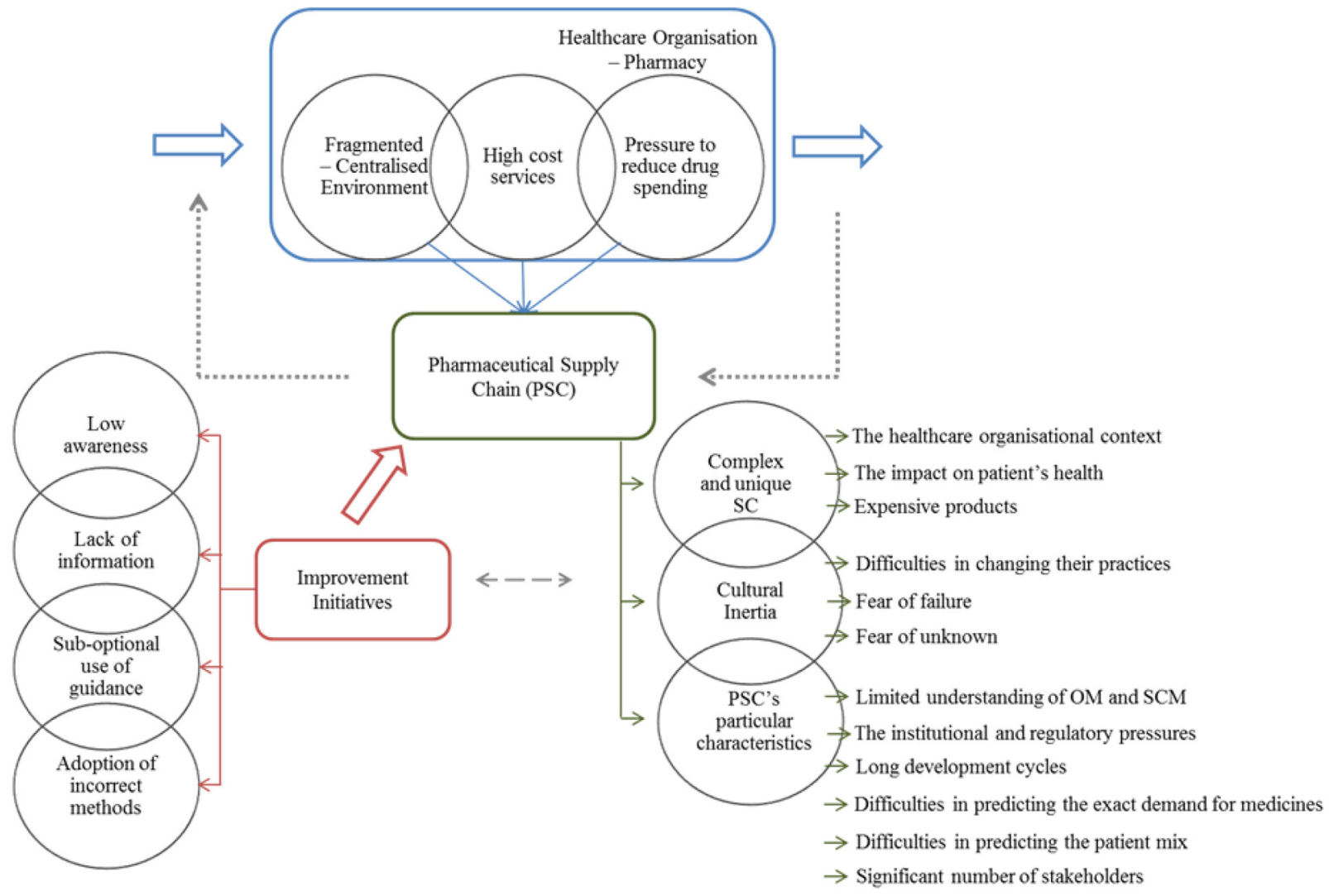


Marina Papalexi, David Bamford and Liz Breen

Table 3 Key facts for the UK and Greece

\begin{tabular}{|c|c|c|c|}
\hline & UK & Greece & $\overline{\text { OECD average }}$ \\
\hline Population & 66.02 million & 10.77 million & - \\
\hline GDP & US\$2.622tn & US\$200.3bn & - \\
\hline \multicolumn{4}{|l|}{ Healthcare expenditure } \\
\hline Health expenditure (as a \% GDP) & 9.6 & 8.4 & 9.0 \\
\hline $\begin{array}{l}\text { Public expenditure on health } \\
\text { as a } \% \text { GDP) }\end{array}$ & 7.6 & 5.1 & 7.3 \\
\hline $\begin{array}{l}\text { Out-of-pocket payments for health care } \\
\text { as a } \% \text { GDP) }\end{array}$ & 2.1 & 3.2 & 2.5 \\
\hline Pharmaceutical expenditure (\% health expenditure) & 11.4 & 26.3 & 15.9 \\
\hline \multicolumn{4}{|l|}{ Healthcare resources } \\
\hline Number of physicians (per 1000 population) & 2.8 & 6.2 & 3.4 \\
\hline Number of nurses (per 1000 population) & 7.9 & 3.3 & 9.0 \\
\hline
\end{tabular}

Table 3 demonstrates that the two selected countries are different in size considering their population and GDP and in the total expenditure on healthcare - Organisation for Economic Cooperation and Development (OECD) Health Data (2018) suggested a positive relationship between GDP and health expenditure. However, Greece spent proportionally more on pharmaceuticals (26.3\% health expenditure, in 2017) than the UK (11.4\% health expenditure, in 2017). Besides, the healthcare system applied in the two selected contexts is different. The UK healthcare system emphasises on developing the primary healthcare settings to promote health and deal with disease at an early stage (Lionis et al., 2009). On the other hand, the Greek healthcare system focusses more on curative services (Souliotis and Lionis, 2005). This is supported by the fact that the share of public resource spent on healthcare in the UK is greater than that in Greece. In addition, the Greek healthcare system involves a higher ratio of physicians and a lower ratio of nurses that the UK healthcare system according to the statistics presented in Table 3.

Therefore, the striking differences between the two locations are the reasons for selecting them; there are differences between these two countries in terms of their healthcare spending and healthcare structure. For example, it is reasonable to suggest that the Greek healthcare system has been constantly affected by the economic crisis, which has caused remarkable reductions in Greek healthcare expenditure. This was not the case for the UK healthcare system, but there are still pressures put on it to minimise healthcare spending while improving healthcare quality. The authors were interested in investigating the complex pharmaceutical delivery process adopted and applied within the two diverse selected contexts. This exploration has enabled them to identify the similarities and differences between the two delivery systems and gain a better understanding of the downstream domains of the PSC in the European context. As a result, this study could contribute to developing a theoretical and empirical understanding of the broader perspective of the downstream domain of PSC norms that exist in the EU.

\subsection{Research design}

The research presents further empirical research into downstream domain of the PSC emphasising on specific geographical contexts, due to a dearth of informed research in this area. As a result of this, this study opts to adoption a qualitative, exploratory design to address the main and sub-RQs (Tukamuhabwa et al., 2017; Saunders et al., 2015). The qualitative approach adopted aims to gain a better understanding, appreciate the context and its singularities and explore the issues related to the downstream domain of the PSC. It allows the development insight about complex, real-life phenomena, which are difficult to be obtained by adopting different approaches such as an online survey (Ketokivi and Choi, 2014). This has been achieved by undertaking semi-structured research interviews $(N=22)$ with key pharmacy professionals within hospital and community pharmacies in two geographical areas, namely, the UK and Greece. The coding and data analysis, using Thematic Analysis, conclude that there are four themes, which are presented in the following findings section. Figure 3 presents in detail the sequence of activities undertaken to achieve the collection and analysis of the qualitative data.

\subsubsection{Development of semi-structured interviews}

Semi-structured research interviews were conducted to gather exhaustive and comprehensive information to explore the experiences, views and beliefs or motivations of individuals on the medicine delivery process in both Greece and the UK. As Figure 3 illustrates, the design of the interview protocol

Figure 3 Sequence of activities within the qualitative approach

Qualitative Approach

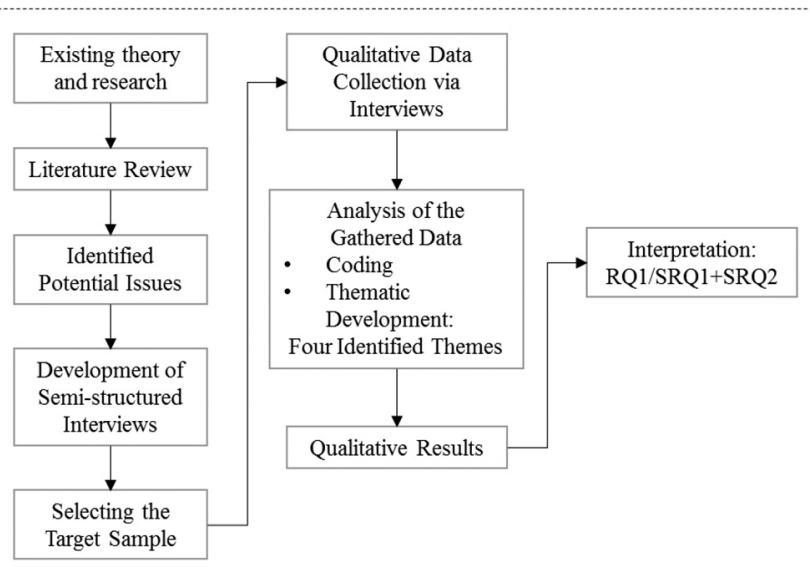


considered the operations and SCM theory and was informed by a preliminary analysis of the existing literature referring to the delivery process of medicines and the issues that have been observed within the downstream domain of the PSC that prevent effective delivery (this is presented in Section 2); the outputs of which identified key areas of exploration, which are the potential PSC issues. The interviews included a list of openended questions, which was divided into three parts:

1 the first part referred to general questions about the study phenomenon and the role of the interviewee therein;

2 the second part included specific questions regarding themes (e.g. the factors preventing an effective delivery process) identified by reviewing reports and previous research; and

3 the third part focussed on the interviewees' personal views and beliefs on whether the perceived issues associated with the system inefficiency could be improved through implementing improvement approaches.

The list of the semi-structured interview questions is presented in the Appendix 1.

\subsubsection{Selecting the target sample}

Researchers select the sample that matches a number of criteria and best answers the RQs, meeting the research aims and objectives (Matthews and Ross, 2010). The target sample involves professionals working in hospital and community pharmacies in the two selected geographical areas. As the research aims to explore the downstream domain of the PSC, only those specialists who work within this domain could be considered as potential participants; therefore, a purposive sampling technique was adopted (Tongco, 2007). The exact number of pharmacists that operate within the particular study area is not available. There is only a general number of those professionals: Greece recorded a high number of professionally active pharmacists, at 104.9 per 100,000 inhabitants in 2016; this number in the UK, in 2016, was 86.2 per 100,000 inhabitants (Eurostat, 2018).

\subsubsection{Qualitative data collection}

In total, 22 semi-structured, face-to-face interviews lasting $1.5 \mathrm{~h}$ on average were undertaken; 16 semi-structured interviews were conducted in the UK and 6 semi-structured interviews took place in Greece. The authors acknowledge that the Greek sample is smaller compared to the UK one. The reason for this is that the authors are based on the UK and access was more readily facilitated because of this. While every attempt was made to engage more Greek participants (directly and via referrals), this proved to be challenging and unfruitful. However the Greek interviews did yield rich data, which was highly informative despite the small sample size. Those interviews provided data to generalise the qualitative research outputs, as the last interview did not add any consequential data. This ensured that the main research content was covered, and thus, the saturation level was reached (O'Reilly and Parker, 2012). Each interview was audio-taped and transcribed verbatim before the data analysis took place. A table that presents an overview of the interviewees' characteristics is provided in the Appendix 2. It discloses information related to participants' background, referring to their role, working experience, qualifications and the innovativeness of the delivery system in which they are involved, based on their perspective. This information adds value to the following analysis, as knowing the background of the interviewees could provide an insight into the participants' reasoning or standpoint regarding some of their views on the phenomenon under investigation.

\subsubsection{Analysis of the gathered data}

A thematic analysis was conducted, which is a foundational method for analysing qualitative data (Guest et al., 2012). This tool enables researchers to identify, report and analyse themes within the collected data. Themes organise a group of repeating ideas, which allows researchers to answer the RQs (Vaismoradi et al., 2016). Braun and Clarke's (2013) linear model was used to conduct the thematic analysis; their model includes six procedures:

1 Familiarisation with the data;

2 Generation of initial codes;

3 Searching for themes;

4 Reviewing themes;

5 Defining and naming themes; and

6 Producing the final report.

In particular, having transcribed the recordings, a list of thematic codes was generated; this process was influenced by the conceptual framework, deductively informed by the literature review and the authors' research interest. Basit (2003, p. 144) highlighted the importance of the coding process by stating that codes or categories are tags or labels for allocating units of meaning to the descriptive or inferential information compiled during a study. Each interview transcript was closely examined and coded manually using MS Excel; the authors acknowledge that the same process could have been delivered by using a software package such as NVivo. Computer software packages have been developed under a certain epistemology, which does not necessarily fit with the purposes of the study (Petty et al., 2012). For this reason, a systematic process of identifying the core themes that meet the research aims and objectives was conducted manually. The coding was done by one person but regular checks on the themes generated were completed by an additional researcher independently as an assurance check (Saldana, 2013). Section 4 presents the findings emerged from the qualitative data analysis.

\section{Findings - the analysis of the emergent themes}

The qualitative data analysis revealed key factors that impact upon the effective delivery of medicines in the UK and Greece. Braun and Clarke's (2013) linear model was used to conduct the thematic analysis; this was introduced in section three. These factors were categorised under four themes, which emerged from the data and literature and which are explained and justified more fully in the subsequent sections:

1 Financial issues;

2 Communication issues;

3 Waste issues; and

4 Complexity issues.

Other interesting data categories became evident during the process of identifying the core themes, but they were not in the immediate focus of this research, and thus, were not used. Of course, different data patterns could inspire future research. 
Each of the identified themes accompanied with evidence from the interviews are presented in Table 4.

\subsection{Financial issues}

The first theme is related to the financial issues that pharmacies have to deal with. The literature is rich in evidence revealing a pressure on healthcare organisations to minimise their expenditure (Al-Balushi et al., 2014). A critical issue identified was the high cost of the produced services. As $8 / \mathrm{UK}$ stated, clinical commissioning groups have extensively focussed on the drug expenditure. Trying to control their pharmaceutical spending, specific budgets are allocated to each healthcare organisation; 7/UK explained, we manage and supply approximately f40m of medication per annum. 18/Gr explained that we cannot spend more than the budget that has been allocated for us, which is approximately $€ 30 m$ per annum. In a similar vein, community pharmacies have to carefully manage the complex pharmaceutical delivery system to be able to predict the demand, satisfy their customers and control their expenses. The budget spent on pharmaceutical depends on the business size and the market demand. For example, according to $16 / \mathrm{Gr}$, a medium size community pharmacy in Greece spend approximately 500,000€per annum.

Healthcare organisations in the UK, try to keep the patients at the primary health care level and this has been considered a way of reducing the cost of services. 12/UK explained that there is a big push to reduce the demand for secondary healthcare service because they are expensive. There is a slightly different view in healthcare organisations in Greece; they tend to keep patients in hospital to avoid any risks associated with their health, although they acknowledge that this practice is too expensive, as $14 / \mathrm{Gr}$ explained. Based on the qualitative data, a "home care practice" has not been adopted by the Greek healthcare system, which might be the reason for a longer hospital treatment. Furthermore, when the interviewees were asked about the adoption of improvement interventions, the majority of them agreed that any improvement requires new investments, which are not available (e.g. 15/Gr and 2/UK).

\subsection{Communication issues}

Communication issues emerged as another important factor that could influence the accurate delivery of medicines; the existence of fragmentation and duplication in services has been reported (Bamford et al., 2015). Specifically, the communication between the different stakeholders involved within the PSC is weak. A UK pharmacist $(11 / \mathrm{UK})$ stated that there is often lack of communication between secondary care and primary care, which contributes to the generation of duplication in services. A Greek pharmacist $(17 / \mathrm{Gr})$ commented on this expressing a different point of view; sometimes there is not enough information provided in a prescription, which makes us unable to deliver it, so we have to contact the doctors asking for additional information. Besides the miscommunication between the prescribers or between them and the pharmacists, there are similar incidents between pharmacies and their suppliers. 23/UK explained that it is really hard to contact our supplier if we need any additional information; it is often a time-consuming process, which might raise the risk of losing customers or making them unsatisfied (e.g. 16/Gr and 1/UK).

Table 4 the Emerged themes with evidence from the interviews

\begin{tabular}{|c|c|c|c|}
\hline Data sources & Themes & Frequencies & Example quotations \\
\hline \multirow[t]{4}{*}{$\begin{array}{l}\text { Number of interviews: } 22 \\
\text { Number of words per } \\
\text { interview: between } 5,105 \text { to } \\
14,461 \\
\text { Total number of themes: } 67\end{array}$} & Financial issues & 510 & $\begin{array}{l}\text { - "It is hard to undertake any improvements when you try to minimise the cost of } \\
\text { the service that we offer. Such initiatives require the investment of a particular } \\
\text { amount of money, which is not always available" (15/Gr) } \\
\text { - "Healthcare organisations try to reduce the cost of the existent system; there is no } \\
\text { space for new investments, especially when nobody can guarantee their success" } \\
\text { (2/UK) }\end{array}$ \\
\hline & $\begin{array}{l}\text { Communication } \\
\text { issues }\end{array}$ & 421 & $\begin{array}{l}\text { - "There is often lack of communication between secondary care and primary care, } \\
\text { so sometimes people get double prescriptions or medications changed yet primary } \\
\text { care do not know and as a result they are still prescribing the other medication" } \\
\text { (11/UK) } \\
\text { " "There are incidents where the medication has been processed, but the doctor } \\
\text { had changed the prescription without us being informed" }(18 / \mathrm{Gr})\end{array}$ \\
\hline & Waste issues & 862 & $\begin{array}{l}\text { - "Patients are not willing to return the spare medication back to the pharmacy } \\
\text { because on one hand having some medicines makes them feel more secure and } \\
\text { on the other hand they want to keep them because they paid for them" (10/UK) } \\
\text { - "As we are able to receive our order five or six times per day we do not really } \\
\text { store many products, so we do control and manage them effectively. It is rare for } \\
\text { a product to expire. However, in houses' cupboards, you might find many expired } \\
\text { drugs that people simply did not return back to us" (17/Gr) }\end{array}$ \\
\hline & $\begin{array}{l}\text { Complexity } \\
\text { issues }\end{array}$ & 612 & $\begin{array}{l}\text { - "Dealing with sensitive and expensive products makes our job very critical } \\
\text { because we have to make sure that the products that we manage are appropriate } \\
\text { for use" (8/UK) } \\
\text { - "We try to store as few products as we can to be able to manage them properly } \\
\text { and also possibly to prevent having expired items on our shelves; as a result, the } \\
\text { role of suppliers is crucial in the SC" }(15 / \mathrm{Gr})\end{array}$ \\
\hline
\end{tabular}


The communication issues that the community pharmacies have to deal with have been described, thus, far, however in hospital pharmacies the situation is slightly different. A UK hospital pharmacist $(4 / \mathrm{UK})$ stated that:

[...] one of our main problems is that the medication does not follow the patient. This process is associated with two types of miscommunication: i) if the drugs do not get to the accident and emergency assessment units in time and patients have been sent to another ward, they will end up having those drugs re-ordered; and ii) even if the medication has been delivered to those units on time, patients may need to move to another ward without taking their medicines with them, which again causes double ordering.

Besides the patient self-medication, which is the drugs that have been prescribed for a particular patient, the wards stock some medicines, in the ward cupboards, for general use. A Greek hospital pharmacist $(14 / \mathrm{Gr})$, stated that nurses from a different department often come to the pharmacy asking for products without having checked their availability in the ward cupboards. Therefore, miscommunication between the staff not only increases the level of wastage but also increases the time spent to distribute the correct medicines or ascertain their availability. In addition, healthcare providers in both selected countries tend to operate independently, without perceiving that they are part of a wider service process. For example, doctors might change the prescription without informing pharmacists (e.g. $18 / \mathrm{Gr}$ and $4 / \mathrm{UK}$ ). Those actions generate delays and waste during the service production, which increases inefficiency and associated cost.

\subsection{Waste issues}

The third theme preventing the effective and efficient delivery of medicines relates to the level of wastage that exists within the PSC. Uthayakumar and Priyan (2013, p. 52) highlighted that:

Pharmaceutical products can be expensive to purchase and distribute, but shortages of essential medicines, improper use of medicines, and spending on unnecessary or low-quality medicines also have a high cost in terms of wasted resources and preventable illness and death.

Community pharmacists believe that the reason for the high level of wastage derives from the existing system itself; it is related to the way clinicians prescribe and patients' attitude; a Greek community pharmacist $(19 / \mathrm{Gr})$ explained that patients often do not follow their medication, which generates waste. Based on the pharmacists' opinion (e.g. 16/Gr, 17/Gr and 19/Gr), patients in Greece tend to ask for more medication, by visiting different doctors, until they find what they think works for them and on the other hand, different doctors tend to prescribe different medication; the one that they believe it will best treat their patients. Similarly, UK community pharmacists (e.g. 22/UK and $10 / \mathrm{UK}$ ) believe that the waste is generated by the system; people tend to buy their prescription, use it until they feel better and then keep it in their cupboard for future use, but they end up storing many expired medicines (e.g. 17/Gr).

Besides community pharmacists' opinion, hospital pharmacists believe that the main waste derives from the poor communication and the lack of synchronisation between the pharmacy and the wards. Specifically, 6/UK explained that:

[...] the main waste comes from the wards; medication is returned to the pharmacy on a daily basis [...] either because the treatment has changed or because patients left the hospital, without having taken their medication with them.

This medication generates waste because it has to be destroyed as it has been used or ordered for a particular patient as $4 / \mathrm{UK}$ reported. Another type of waste arises from some lines/types of medicines that have to be stored in the pharmacy according to the guidance from the General Pharmaceutical Council. 2/UK explained that:

[...] we have to keep in some type of medicines, such as antidotes for poisoning, just in case they are needed. However, we rarely use them and as a result they often go out of date.

Similarly, the medicines included in the emergency drugs boxes can easily go out of date as they are not used frequently but they have to be kept according to the national guidance. Hospital pharmacies acknowledge the high level of wastage that exists within hospitals and for this reason they have introduced green bins; these are lockable boxes in which leftover or unusable medicines are put. However, according to $5 / \mathrm{UK}$, separating the medicines that can be reused from those that have to be destroyed is a time-consuming process:

[...] we have to make sure that these medicines can be reused, some of them might be unlabelled and according to the guidance from the General Pharmaceutical Council, we cannot re-use them until we have correctly identified them.

\subsection{Complexity issues}

The final theme emerging from the analysis is the perceived complexity issues of the delivery system. A group of scholars suggested that the PSC are more complex compared to SCs in other sectors (Greenhalgh et al., 2012). The type of services offered is enough to represent the level of complexity within this system; 8/UK stated, we have to deal with not only sensitive products but also very expensive ones. It is generally accepted that medicines can be converted into dangerous or useless products for consumers; based on this assumption, Within the PSC there are different distribution lines; they cannot treat all the products that they manage in the same way. $15 / \mathrm{Gr}$ reported:

[...] we store our products differently based on their frequency of use; we want to have easy access to those that are immediately consumed and of course this influences how frequently we order them.

8/UK reiterated this, explaining that the system requires an excellent relationship with our suppliers including a high level of trust.

Hospital pharmacies in both countries tend to receive their medicine supplies twice per day; they have set up a contract with a couple of big wholesalers, which enable them to negotiate the prices and get a better offer. On the other hand, community pharmacies are not in a privileged position where they can set up contracts with their suppliers, but they tend to create collaborations between them or alternatively have their own wholesaler company and supply their stores. In particular, in Greece there are 27 organisations founded by groups of cooperative pharmacists, operating within a particular region. These organisations operate as warehouses; they locate close to their members, which creates flexibility, enabling them to deliver the products on time. In the UK, community pharmacies tend to be big companies with many stores all over the country. They run their own warehouse, which also allow them to get some good deals from the pharmaceutical companies, as $9 / \mathrm{UK}$ explained.

The complexity of the system is not only created from the suppliers but also the existence of multiple stakeholders, as Figure 1 illustrates, also impacts upon the distribution of medicines. Especially, in the PSC there are numerous stakeholders who are responsible for the delivery of medicines 
such as general practitioners (GPs), nurse practitioners (NPs), secondary care doctors and pharmacists. In the UK all of them can prescribe medication or advise patients. On the other hand, in Greece nurses have not been trained to prescribe medication, which is something that only doctors are qualified to do.

In summary, four main sources of operational inefficiency were identified. The issues related to these four themes have been discussed and analysed based on the interviewees' answers. Table 5 presents the qualitative findings, highlighting the main sources of operational inefficiency in the PSC.

\section{Discussion}

To provide clarity to the discussion this section has been arranged around two core areas, namely:

1 The common issues observed within the downstream domain of the PSC; and

2 The region-dependent issues observed within the downstream domain of the PSC, which engages with the findings and literature around the UK and Greece contexts.

\subsection{The common issues observed within the downstream domain of the pharmaceutical supply chain}

As indicated from the literature and confirmed from the data analysis of this study, healthcare organisations have to deal with a number of SC issues when they attempt to produce their services such as financial, complexity, cultural and communication issues (Xie and Breen, 2012; Davies and Edwards, 2013). These issues influence the healthcare service quality and in particular prevent an efficient and effective delivery process (Chassin, 2013). Al-Balushi et al. (2014) stated that constant external pressures impel healthcare organisations to undertake operational changes to minimise their pharmaceutical spending.

The limited financial resources available for healthcare organisation in both countries have acted as a barrier in undertaking any improvements. Pharmacists in both countries assume that the implementation of any new or significantly improved delivery practices requires a particular investment, which cannot be supported by the healthcare organisation as there is no additional funding for them. They seem to be reluctant to undertake any changes because they believe that they are costly and risky. Organisations' financial resources need to support any improvement interventions (Davenport, 2013); the absence of funding might lead those activities to be abandoned or not be completed (Archibugi et al., 2013). "During a crisis, many firms might focus more strongly on survival and less on seeking out new opportunities" (Archibugi et al., 2013, p. 306). However, there are a number of initiatives that can be undertaken that require less or no financial investment and are still able to improve organisations' performance such as Lean thinking or Reverse Logistics (Weingart et al., 2012).

The data analysis demonstrated that in both European contexts, the weak communication and stakeholder synchronisation, undermines the effective performance of the PSC. The main root-cause of the perceived miscommunication is associated with the low level of transparency during the delivery process. This fact could be explained based on the significant gap existing between doctors, nurses and pharmacists' perceptions of their roles in producing healthcare services, including their different attitudes towards teamwork (Maddox et al., 2016). Akhtar et al. (2012) highlighted the importance of teamwork development for improving service effectiveness and achieving the organisation's success. Hwang and Rho (2014) stated that successful SCM requires systematic and strategic management of collaboration, information and knowledge, which fits with the particular political, social and cultural context. Hwang and Rho (2014) explained that actors of SCs have to invest in relationships between them, which could result in benefits of knowledge transfer, information sharing and the establishment of common strategies to explore and exploit potential opportunities.

The analysis of the data found that the level of wastage is high, which causes inefficiency within the pharmaceutical delivery system. The critical role of pharmaceuticals in human health forces pharmacies to retain a large inventory of stock, which increase the risk of generating waste (Bhakoo et al., 2012). One current example of this in practice is the uncertainty surrounding Brexit negotiations in the UK and the potential for panic stockpiling across this SC (Kwon, 2018). In addition, functional rules derived from the particular legal context are evidence of the relatively centralised environment of healthcare organisations (Bamford et al., 2015), which does not allow pharmacists to operate independently and fully control their storage (Papalexi et al., 2015). These practices cause considerable operational problems such as the expiry of medicinal products stored for a long time or critical drug shortages (Kostagiolas et al., 2008). Besides, the data analysis concluded that waste within the PSC is generated due to the lack of communication and synchronisation between the PSC stakeholders. Hospital pharmacists operating in both geographical areas explained that the main waste comes from the wards, either due to the perceived discontinuity in services or due to the poor information sharing between the clinical staff

Table 5 the Main sources of operational inefficiency in the PSC

\begin{tabular}{llll}
\hline Financial issues & Communication issues & Waste issues & Complexity issues \\
\hline $\begin{array}{llll}\text { Expensive healthcare services } \\
\text { Limited financial resources }\end{array}$ & $\begin{array}{l}\text { Lack of communication and synchronisation } \\
\text { Limited information shared between the } \\
\text { different groups of stakeholders }\end{array}$ & $\begin{array}{l}\text { System's inefficiency } \\
\text { Patients and healthcare } \\
\text { providers' culture }\end{array}$ & $\begin{array}{l}\text { Characteristics of medicines } \\
\text { The role of suppliers }\end{array}$ \\
$\begin{array}{l}\text { Difficulties in controlling } \\
\text { pharmaceuticals spending } \\
\text { High cost of innovation }\end{array}$ & $\begin{array}{l}\text { Lack of cross functional understanding of the } \\
\text { process }\end{array}$ & $\begin{array}{l}\text { Lack ortration of the } \\
\text { healthcare resources } \\
\text { Lack of education }\end{array}$ & $\begin{array}{l}\text { The role of the different groups of } \\
\text { stakeholders } \\
\text { Low level of transparency during } \\
\text { the delivery process }\end{array}$ \\
\hline
\end{tabular}


and pharmacists. This matches with the previous literature supporting that physicians tend not to inform pharmacies when they have ceased to prescribe medicines for a particular ailment (Bhakoo et al., 2012). Although, according to Liu and D'Aunno (2011), developing collaborations among health professionals has been considered as one of the most effective strategies to manage patient care, challenges such as misunderstandings of each other's role, differing perceptions towards collaboration (Schadewaldt et al., 2014) and the existence of hierarchical structures (Schadewaldt et al., 2014), need to be faced.

Furthermore, community pharmacies, in both European contexts, believe that the waste within the PSC derives from the healthcare system. This is in line with published reports identifying root causes of medicine waste, encompassing:

[...] patients recovering before their dispensed medicines have all been taken; therapies being stopped or changed because of unwanted side effects; patients' deaths; and factors relating to repeat prescribing and dispensing processes. (DoH, 2011, p. 6)

Kongar et al. (2014) suggested, that most of the time, the spare medicines are not returned into the system. Those products can be converted into dangerous or useless products; a fact that has raised significant concerns for potential threat to ecological environment and human health (Department of Health (DoH), 2014). Wang et al. (2015) stated that there are evidence revealing that pharmaceuticals have been detected in various environmental compartments such as surface water and groundwater. For this reason, the EU, in 2011, developed a public awareness campaign aiming to reduce the impact on the health and environment generated by hazardous waste, including expired or unwanted medicines, through their safe disposal (Kongar et al., 2014).

Attempts to explain the complexity of the delivery system concluded that, from an operations point of view, the use of simplistic push logistics might be the answer to the current process inefficiency. Jamali et al. (2010) explained that a pushbased SC is based on forecast demand, which provides direction on the quantity and type of products that need to be stored. However, Bhakoo et al. (2012) suggested that within the PSC, high demand uncertainty has been observed, not only because of the nature of the pharmaceutical products but also because of the existence of the institutional and regulatory pressures.

Furthermore, Scheller and Smeltzer (2006) reported that physicians' knowledge regarding OM and SCM practices is limited, which increases the complexity of the delivery system. Although clinicians' role is to focus on patients care rather than administrative functions, critical management skills are required to deliver high quality services (Breen and Xie, 2015). Uthayakumar and Priyan (2013) suggested that these skills could solve inventory management problems and as a result improve the healthcare operations. It is apparent, therefore, that the stakeholders involved within the PSC require expert knowledge to be able to best use the healthcare organisational resources, avoid the duplication in services and as a result improve customer satisfaction (Radnor et al., 2012).

The availability and quality of medicines do not rely only on the pharmacists' ability to manage them properly but also on the role of suppliers; the availability and quality are based on how frequently they deliver the required products. According to Hakansson et al. (2009), managing the relationships between organisations and their suppliers is critical for the SCM because this influences the organisations' performance.

From the analysis of the data, it was established that a number of similar issues have been observed in the pharmaceutical delivery systems implemented within the two diverse contexts (UK and Greece). These issues cause considerable operations problems, preventing an effective and efficient PSC. Figure 4 presents the emerging sources of

Figure 4 Issues observed within the PSC in both European contexts

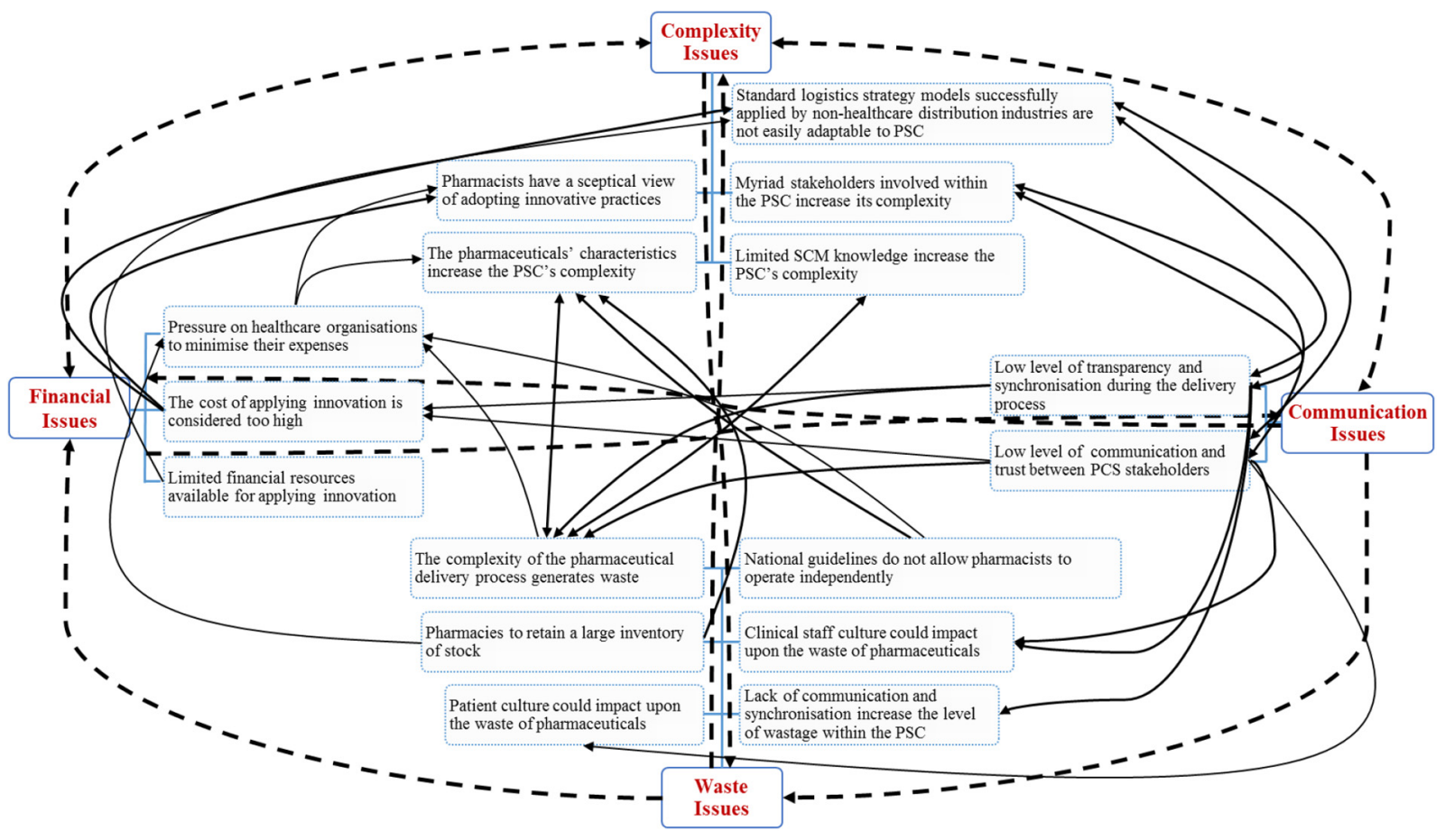


inefficiency, which are associated with the four primary themes, namely:

1 finance;

2 communication;

3 waste; and

4 complexity.

By discussing those issues, it became apparent that there is a multi-dimensional relationship between an issue and a theme. For example, the lack of synchronisation and continuity of services primarily emerged as a communication issue; however, it also increased the complexity of the system and impacted on the level of wastage. In Figure 4, the wider dashed line represents the relationship between the themes and the solid lines present the relationship between the issues. The complexity of relationships is potentially different amongst the solid arrows, but it is very difficult to illustrate with confidence between the perceived issues and the presented weight of importance. The figure does, however, provide a visual indication based on the qualitative data and analysis.

\subsection{The region-dependent issues observed within the downstream domain of the pharmaceutical supply chain}

The healthcare system in the UK has had significant financial and infrastructural development over the past decade. This has facilitated provision of services closer to patients' homes; therefore, the demand on hospital outpatient departments has been reduced. For this practice to be implemented successfully, the national health service (NHS) in the UK has educated the clinical staff such as the NPs, to be able to assess patients' condition and prescribe medication (Gielen et al., 2014). As Kroezen et al. (2011) explained, the introduction of nurse prescribing was aimed at improving the access quality and continuity of care. However, Sandø et al. (2010) highlighted that the existence of multiple prescribers within the UK healthcare system increases the complexity of the pharmaceuticals delivery process and the higher potential of medicines waste.

The Department of Health (2011, p. 6) reported that one of the main root causes of medicine waste derived from therapies being stopped or changed because of ineffectiveness and side effects, which is one of the reasons why medicine optimisation is such a huge agenda. The waste of pharmaceutical products might be generated not only because treatments are changed because of the prescribers' different opinions (Sandø et al., 2010) but also because of patients' attitude. Nunes et al. (2009) found that approximately one-half of the medication prescribed for long-term conditions is not taken as recommended. Patients, therefore, sometimes decide not to follow the guidelines provided, either because they feel better or they believe the medication is not appropriate for their condition. Considering the lack of communication and synchronisation existing between the PSC stakeholders and in particular between the physicians and the clinical staff (Bhakoo et al., 2012), one could appreciate the communication issues occurring due to the involvement of multiple prescribers in the system. As detailed above, this also generates financial and waste issues because providing different medication means that patients need to buy different medicines and that the spare medication is no longer useful.

Focussing on the Greek healthcare system, only physicians can prescribe medication, which reveals a rather fragmented and centralised system. Considering that the Greek healthcare system involves one of the highest ratios of physicians and one of the lowest ratios of nurses in Europe, one could conclude that the emphasis has been placed on curative services rather than disease prevention, health promotion and home care services, which is something supported by Lionis et al. (2009). As the NHS in Greece has not developed a well-established primary care, patients tend to trust more the private primary care providers. Lionis et al. (2009, p. 2) stated that "the Greek healthcare system is one of the most privatised among EU countries". In 2017, the private expenditure of overall health spending in Greece, accounted for 39\% (OECD Health Data, 2019); this percentage is double that (21\%) covering the relative services produced in the UK (OECD Health Data, 2019). According to Theodorou et al. (2009), this practice has greatly contributed to the discontinuity of healthcare services because patients are free to select and consult with any specialist, who may provide different guidelines. Therefore, although there is only one type of prescribers, high level of wastage is still generated (Pappa and Niakas, 2006). Gress et al. (2006) suggested that the non-existence of family physicians serving as gatekeepers to more specialised care and the miscommunication between the healthcare providers, increases spending on pharmaceuticals and associated waste. This is because more medicines are likely to be prescribed and therapies stopped or changed. The pharmaceuticals delivery process, therefore, is characterised as highly complex, similar to the UK delivery system; however, this complexity is generated by applying different practices.

As can be concluded from Table 6, although the UK and Greek healthcare systems have been structured in a different manner, based on the available resources and capacity, the issues emerging are similar and related to the primary themes identified:

- financial;

- communication;

- waste; and

- complexity.

One could conclude that the issues related to systems do not stem from the system itself but from the way of managing it. BrandonJones et al. (2014) suggested that orchestrating resources and capabilities across the SC could be very challenging, but at the same time creates opportunities of developing an effective system. For example, the primary care provision can be developed within the Greek healthcare system implementing a GP's practice for the identified issues to be overcome (Lionis et al., 2009). Although developing the primary care provision can lead to less expensive healthcare services through better controlling the overall healthcare costs (Ansari et al., 2003), maintaining a strong primary care structure requires great investments (Rosano et al., 2011). Therefore, this initiative has to fit with the Greek context, considering the Greek healthcare organisations' characteristics to be successfully implemented. Similarly, improvements within UK primary care have to be undertaken based on the available sources and capabilities. Barney (2015), who focussed on organisational systems' effectiveness, suggested that internal 
Marina Papalexi, David Bamford and Liz Breen

Table 6 A Summary of the key differences between the Greek and UK PSCS

The issues associated within the PSC

The UK context

Strong primary healthcare structure

Existence of multiple prescribers

Differences in prescribing process

- Differences in prescribing practices between NPs and physicians

\section{The Greek context}

Weak primary healthcare structure

Existence of only one prescriber - physicians

More "privatised" healthcare system

- Non-existence of family physicians serving as gatekeepers to more specialised care

Increasing complexity of the PSC

Increasing spending on pharmaceuticals

Increasing level of wastage

Difficulties in the healthcare providers' communication system

weaknesses and external threats can be avoided through establishing strategies that fit with organisations' environmental conditions.

\section{Conclusions}

The aim of this research was to assess the downstream domain of the PSC taken place within the UK and Greece; the identified issues could be considered for innovative approaches to be implemented aiming to improve the medicine delivery system. Although, there is a wealth of research that explores PSC management and strategy, few studies have been reported in the literature, which adopts a focussed approach on downstream PSC activity and also as a cross-case comparative analysis. In this study, there is an incremental and revelatory contribution (Nicholson et al., 2018) as it attempts to rectify this imbalance and there are four key outputs as follows:

1 This study fills the gap in literature on the subject of SCM not only in hospitals but also in community pharmacies operating in two different geographical areas, the UK and Greece. Specifically, this research extends the work of previous studies e.g. conducted by Xie and Breen (2014) on waste management; Bhakoo et al. (2012) on inventory management; and Burnes and Jackson (2011) on change management in healthcare;

2 It also contributes to the academic literature by investigating the downstream domain of the PSC, using hospital and community pharmacies as the focal organisations. Previous research examining the aspect of PSC mainly focussed on the upstream domain of the PSC that includes the pharmaceutical manufacturers (Narayana et al., 2014). Figure 1 provides a conceptual model of the PSC domains and identifies the number of stakeholders involved in them;

3 The current research summarises the key issues related to the PSC inefficiency reported in the existing relevant literature, which are represented by Figure 2 and identifies 4 key areas inefficiency that impact upon both the UK and Greek PSCs: 1. financial, 2. communication, 3. waste and 4. complexity issues. In addition, the paper highlights the common issues observed in both selected countries, which provides a more clarity to the pharmaceutical delivery process applied in the European context, allowing the generalisation of the research findings; and the regiondependent issues, which can be considered by each country to avoid ineffective practices; and
4 This paper provides more information regarding the practices involved with the downstream domain of the PSC highlighting the areas that require improvements. This information can help healthcare organisations to address a critical issue for academics and practitioners, which is related to the challenge of how healthcare organisations could be more productive, whilst using fewer resources (Mustaffa and Potter, 2009; Xie and Breen, 2012; Al-Balushi et al., 2014).

\subsection{Practical implications}

This research is exploratory in nature and provides further theoretical insights to SC strategy development. Its results identified four key areas of intervention needed within the downstream PSC. These results potentially assist hospital and community pharmacists to understand the operational inefficiencies that they have to face and directs them towards suitable innovative solutions that could enable them to increase levels of efficiency and effectiveness. This research examines the healthcare SCs in two European contexts, the study's outputs, therefore, provide information regarding ineffective practices or best delivery practices implemented in the UK and Greece - a knowledge exchange contribution between the two countries. Finally, the paper highlights the practices within the medicines delivery process that require improvements; those, which could help healthcare organisations to address a critical issue for academics and practitioners, namely the challenge of how healthcare organisations could be more productive using fewer resources (Mustaffa and Potter, 2009; Xie and Breen, 2012; Al-Balushi et al., 2014).

\subsection{Limitations}

One of the major challenges faced while conducting this research was related to accessing the required data. Considering that professionals working within the PSC have a relatively heavy work load, a number of the potential participants were reluctant to be involved in this research. In addition to this, the study focusses only on the downstream domain of the PSC, which excludes those specialists operating within the upstream and central PSC domain. Another obstacle faced particularly during the data collection was related to the geographical distance; the authors approached only the potential participants that could be reached, thus the difference in responses rates between the UK and Greek sample. Finally, the last limitation of this research stemmed from the way that 
the data analysis was conducted. The thematic analysis undertaken was driven by the literature review and the authors' theoretical and analytic interest, which might have influenced the interpretation. The authors acknowledge that ultimate objectivity was difficult to achieve, as this is the case in most qualitative social research studies. However, this limitation was addressed through transcribing all interviews and using respondents' direct quotes to support the research findings. The authors also recognise that the qualitative data could have generated different data patterns that could be used for inspiration for conducting further future research.

\subsection{Future research}

This research focusses on the PSC downstream practices, it would also be valuable to examine and investigate the PSC as a whole to understand the influences generated by other stakeholders' actions such as the pharmaceutical companies. While this research provides insights into the factors that might affect the pharmacies' efficiency, concentrating on the whole PSC could add more information, based on which a more reliable research could be achieved. In addition, as the current study is considered qualitative, a more quantitative strategy is a possible evolution of the study. For example, analysing the issues that emerged using structural equation modeling could allow their prioritisation, based on their relative weight of importance (Singh et al., 2013). This approach will help healthcare organisations to emphasise those component parts that are responsible for the highly complex delivery system, and thus, it will facilitate the decision-making process on synthesising a solution. The theoretical perspective of this study generates also another avenue of future research, which would be to identify innovative approaches that could be implemented to enhance the performance of PSCs. Furthermore, although in this research the delivery practices applied within two diverse geographical areas were compared; future research is required on the PSC strategies that are adopted by different European countries and across European boundaries. A comparison between the PSC used in Europe and that existing in the USA or Australia is suggested as the healthcare system operating in these geographical areas is different than the European one, although perhaps similar in terms of population density and socio economics. It would be very interesting to identify differences and/or similarities between those areas and Europe. This type of research might highlight some pharmaceutical delivery best practices that could be transferred. In addition to this, future studies could improve the generalisability of the research findings if they are conducted in other sectors such as the food industry. Food products are considered to have similar characteristics to pharmaceuticals, considering their short expiration date and their impact on society.

\section{References}

Akhtar, N., Lindenmeyer, A., Cooke, M. and Perkins, G. (2012), "Influence of in-hospital cardiac arrest team dynamics on team performance: mixed method case study", Resuscitation, Vol. 83, pp. 28-42.

Al-Balushi, S., Sohal, A.S., Singh, P.J., Al Hajri, A., Al Farsi, Y.M. and Al Abri, R. (2014), "Readiness factors for lean implementation in healthcare settings - a literature review",
Fournal of Health Organization and Management, Vol. 28 No. 2, pp. 135-153.

Alvesson, M. and Gabriel, Y. (2013), "Beyond formulaic research: in praise of greater diversity in organizational research and publications", Academy of Management Learning E Education, Vol. 12 No. 2, pp. 245-263.

Ansari, Z., Barbetti, T., Carson, N.J., Auckland, M.J. and Cicuttini, F. (2003), "The Victorian ambulatory care sensitive conditions study: rural and urban perspectives", Soz Praventivmed., Vol. 48 No. 1, pp. 33-43.

Archibugi, D., Filippetti, A. and Frenz, M. (2013), "Economic crisis and innovation: is destruction prevailing over accumulation?", Research Policy, Vol. 42 No. 2, pp. 303-314.

Bam, L., McLaren, Z.M., Coetzee, E. and von Leipzig, K.H. (2017), "Reducing stock-outs of essential tuberculosis medicines: a system dynamics modelling approach to supply chain management", Health Policy and Planning, Vol. 32 No. 8, pp. 1127-1134.

Bamford, D., Forrester, P., Dehe, B. and Leese, R. (2015), "Partial and iterative lean implementation: two case studies", International fournal of Operations \& Production Management, Vol. 35 No. 5, pp. 702-727.

Baraldi, E., La Rocca, A. and Perna, A. (2014), "Good for science, but which implications for business? An analysis of the managerial implications in high-impact B2B marketing articles published between 2003 and 2012", Fournal of Business \& Industrial Marketing, Vol. 29 Nos 7/8, pp. 574-592.

Barney, J. (2015), "Firm resources and sustained competitive advantage", International Business Strategy: Theory and Practice, Routledge, New York, NY.

Basit, T. (2003), "Manual or electronic? The role of coding in qualitative data analysis", Educational Research, Vol. 45 No. 2, pp. 143-154, doi: 10.1080/0013188032000133548.

Bhakoo, V., Singh, P. and Sohal, A. (2012), "Collaborative management of inventory in Australian hospital supply chains: practices and issues", Supply Chain Management: An International fournal, Vol. 17 No. 2, pp. 217-230.

Birkie, S.E., Trucco, P. and Campos, P.F. (2017), "Effectiveness of resilience capabilities in mitigating disruptions: leveraging on supply chain structural complexity", Supply Chain Management: An International fournal, Vol. 22 No. 6, pp. 506-521.

Brandon-Jones, E., Squire, B., Autry, C. and Petersen, K. (2014), "A contingent resource-based perspective of supply chain resilience and robustness", Fournal of Supply Chain Management, Vol. 50 No. 3, pp. 55-73.

Braun, V. and Clarke, V. (2013), Successful Qualitative Research: A Practical Guide for Beginners, Sage, London.

Breen, L. and Xie, Y. (2015), "Waste not, want not. What are the drivers of sustainable medicines recycling in national health service hospital pharmacies (UK)?”, International fournal of Procurement Management, Vol. 8 Nos 1/2, p. 82.

Brown, S., Bessant, J. and Lamming, R. (2013), Strategic Operations Management, 3rd ed., Routledge.

Burnes, B. and Jackson, P. (2011), "Success and failure in organizational change: an exploration of the role of values", Fournal of Change Management, Vol. 11 No. 2, pp. 133-162. 
Chassin, M. (2013), "Improving the quality of health care: what's taking so long?”, Health Affairs, Vol. 32 No. 10, pp. 1761-1765.

Chen, X., Yang, H. and Wang, X. (2019), "Effects of price cap regulation on the pharmaceutical supply chain", fournal of Business Research, Vol. 97, pp. 281-290.

Cheng, J.L.C., Henisz, W.J., Roth, K. and Swaminathan, A. (2009), "From the editors: advancing interdisciplinary research in the field of international business: prospects, issues and challenges", fournal of International Business Studies, Vol. 40 No. 7, pp. 1070-1074.

Cherrett, T.J., Maynard, S., McLeod, F.N. and Hickford, A.J. (2012), "Reverse logistics for the management of waste", in McKinnon, A. (Ed.), Green Logistics: Improving the Environmental Sustainability of Logistics, Kogan, London, GB, pp. 242-262.

Chowdhury, MD., Hossan, M. and Quaddus, M. (2016), "Supply chain readiness, response and recovery for resilience", Supply Chain Management: An International fournal, Vol. 21 No. 6, pp. 709-731.

D'Este, P., Iammarino, S., Savona, M. and von Tunzelmann, N. (2012), "What hampers innovation? Revealed barriers versus deterring barriers", Research Policy, Vol. 41 No. 2, pp. 482-488.

Davenport, T.H. (2013), Process Innovation: reengineering Work through Information Technology, Harvard Business School Press.

Davies, B. and Edwards, N. (2013), "Sustaining Knowledge Use. In Knowledge Translation in Health Care: Moving from Evidence to Practice, Straus, S.E., Tetroe, J. and Graham, I.D. (Eds), Wiley-Blackwell, West Sussex, UK, pp. 165-173.

De Vries, J. and Huijsman, R. (2011), "Supply chain management in health services: an overview", Supply Chain Management: An International fournal, Vol. 16 No. 3, pp. 159-165.

Department of Health (DoH) (2011), "Evaluation of the scale, causes and costs of waste medicines", available at: www.gov. uk/government/publications/making-best-use-ofmedicinesreport-of-a-department-of-health-roundtableevent-hostedby-the-king-s-fund (accessed 30 November 2013).

Department of Health (DoH (2014), "Corporate report 2013 to 2014", available at: www.gov.uk/government/publications/ department-of-health-corporate-plan-2013-14/department-ofhealth-2013-14-corporate-plan

Ding, B. (2018), "Pharma industry 4.0: literature review and research opportunities in sustainable pharmaceutical supply chains", Process Safety and Environmental Protection, Vol. 119, pp. 115-130.

European Commission (2015), "Legal framework governing medicinal products for human use in the EU', available at: http:// ec.europa.eu/health/human-use/legal-framework/index_en.htm

European Medicines Agency (2014), "The European regulatory system for medicines and the European medicines agency: a consistent approach to medicines regulation across the European union", Science Medicines Health, available at: www.ema.europa.eu/docs/en_GB/document_library/Brochure/ 2014/08/WC500171674.pdf

Eurostat (2018), "Healthcare personnel statistics - dentists, pharmacists and physiotherapists", available at: https://ec.
europa.eu/eurostat/statisticsexplained/index.php/Healthcare_ personnel_statistics_dentists,_pharmacists_and_physiotherapists

Ferreira, D., Marques, R. and Nunes, A. (2018), "Economies of scope in the health sector: the case of portuguese hospitals", European Fournal of Operational Research, Vol. 266 No. 2, pp. 716-735.

Førsund, F. (2017), "Measuring effectiveness of production in the public sector”, Omega, Vol. 73, pp. 93-103.

Gielen, S., Dekker, J., Francke, A., Mistiaen, P. and Kroezen, M. (2014), "The effects of nurse prescribing: a systematic review", International fournal of Nursing Studies, Vol. 51 No. 7, pp. 1048-1061.

GöLgeci, I., and and Ponomarov, S.Y. (2015), "How does firm innovativeness enable supply chain resilience? The moderating role of supply uncertainty and interdependence", Technology Analysis E Strategic Management, Vol. 27 No. 3, pp. 267-282.

Greenhalgh, T., Macfarlane, F., Barton-Sweeney, C. and Woodard, F. (2012), "If we build it, will it stay? A case study of the sustainability of whole-system change in London", Milbank Quarterly, Vol. 90 No. 3, pp. 516-547.

Greenwood, D., Tully, M.P., Martin, S. and Steinke, D. (2019), "The description and definition of emergency department pharmacist practitioners in United Kingdom (the ENDPAPER study)", International fournal of Clinical Pharmacy, Vol. 41 No. 2, pp. 434-444.

Gress, S., Delnoij, D. and Groenewegen, P. (2006), "Managing primary care behaviour through payment systems and financial incentives", in Saltman, R., Rico, A., Boerma, W.G.W., (Eds), Primary Care in the Driver's Seat? Organizational Reform in European Primary Care, Open University Press, Buckingham, pp. 184-200.

Guerrini, A., Romano, G., Campedelli, B., Moggi, S. and Leardini, C. (2018), "Public vs private in hospital efficiency: exploring determinants in a competitive environment", International fournal of Public Administration, Vol. 41 No. 3, pp. 181-189.

Guest, G., MacQueen, K.M. and Namey, E.E. (2012), Applied Thematic Analysis, Sage, Thousand Oaks, CA.

Hakansson, H., Ford, I.D., Gadde, L.E., Snehota, I. and Waluszewski, A. (2009), Business in Networks, Wiley, Chichester.

Hwang, Y. and Rho, J. (2014), "Strategic value of RFID for inter-firm supply chain networks: an empirical study from a resource and social Capital perspective", Information Development, Vol. 32 No. 3, pp. 509-526.

Jamali, D., Hallal, M. and Abdallah, H. (2010), "Corporate governance and corporate social responsibility: evidence from the healthcare sector", Corporate Governance: The International Fournal of Business in Society, Vol. 10 No. 5, pp. 590-602.

Kannampallil, T., Schauer, G., Cohen, T. and Patel, V. (2011), "Considering complexity in healthcare systems", Fournal of Biomedical Informatics, Vol. 44 No. 6, pp. 943-947.

Ketokivi, M. and Choi, T. (2014), "Renaissance of case research as a scientific method", fournal of Operations Management, Vol. 32 No. 5, pp. 232-240.

Kongar, E., Haznedaroglu, E., Abdelghany, O. and Bahtiyar, M. (2014), "A novel IT infrastructure for reverse logistics 
operations of end-of-life pharmaceutical products", Information Technology and Management, Vol. 16 No. 1, pp. 51-65.

Kostagiolas, P., Kaitelidou, D. and Hatzopoulou, M. (2008), Improving the Quality of Health Services, Papasotiriou, Athens.

Kroezen, M., van Dijk, L., Groenewegen, P.P. and Francke, A.L. (2011), "Nurse prescribing of medicines in Western European and Anglo-Saxon countries: a systematic review of the literature", BMC Health Services Research, Vol. 11 No. 1, p. 127.

Kwon, D. (2018), "The UK pharmaceutical industry braces for brexit", The Scientist, available at: www.the-scientist. com/news-opinion/the-uk-pharmaceutical-industry-bracesfor-brexit-64926 (accessed 11 February 2019).

Liddell, A., Adshead, S. and Burgess, E. (2008), Technology in the NHS: transforming the Patient's Experience of Care, Kings Fund, London.

Lionis, C., Symvoulakis, E., Markaki, A., Vardavas, C., Papadakaki, M., Daniilidou, N., Souliotis, K. and Kyriopoulos, I. (2009), "Integrated primary health care in Greece, a missing issue in the current health policy agenda: a systematic review", International fournal of Integrated Care, Vol. 9 No. 3, pp. 1568-4156.

Liu, N. and D'Aunno, T. (2011), "The productivity and costefficiency of models for involving nurse practitioners in primary care: a perspective from queuing analysis", Health Services Research, Vol. 47 No. 2, pp. 594-613.

Maddox, C., Halsall, D., Hall, J. and Tully, M. (2016), "Factors influencing nurse and pharmacist willingness to take or not take responsibility for non-medical prescribing", Research in Social and Administrative Pharmacy, Vol. 12 No. 1, pp. 41-55.

Matthews, B. and Ross, L. (2010), Research Methods: A Practical Guide for the Social Sciences, Pearson Education, Essex.

Medical Waste Management Market (2018), "Markets and markets research", available at: www.marketsandmarkets. com/Market-Reports/medical-waste-management-market1256.html

Mustaffa, N.H. and Potter, A. (2009), "Healthcare supply chain management in Malaysia: a case study", Supply Chain Management: An International fournal, Vol. 14 No. 3, pp. 234-243.

Narayana, S., Kumar Pati, R. and Vrat, P. (2014), “Managerial research on the pharmaceutical supply chain - a critical review and some insights for future directions", fournal of Purchasing and Supply Management, Vol. 20 No. 1, pp. 18-40.

Narayanamurthy, G., Gurumurthy, A., Subramanian, N. and Moser, R. (2018), "Assessing the readiness to implement lean in healthcare institutions - a case study", International Fournal of Production Economics, Vol. 197, pp. 123-142.

National Organisation for Medicines. (NOfM) (2016), "The organisation's aim and objectives", available at: www.eof.gr/ web/guest/information

Nicholson, J., LaPlaca, P., Al-Abdin, A., Breese, R. and Khan, Z. (2018), "What do introduction sections tell us about the intent of scholarly work: a contribution on contributions", Industrial Marketing Management, Vol. 73, pp. 206-219.

Nunes, V., Neilson, J., O’Flynn, N., Calvert, N., Kuntze, S., Smithson, H., Benson, J., Blair, J., Bowser, A., Clyne, W., Crome, P., Haddad, P., Hemingway, S., Horne, R., Johnson, S., Kelly, S., Packham, B., Patel, M. and Steel, J. (2009), Clinical Guidelines and Evidence Review for Medicines
Adherence: Involving Patients in Decisions about Prescribed Medicines and Supporting Adherence, National Collaborating Centre for Primary Care and Royal College of General Practitioners, London.

O'Reilly, M. and Parker, N. (2012), "Unsatisfactory saturation: a critical exploration of the notion of saturated sample sizes in qualitative research", Qualitative Research fournal, Vol. 13 No. 2, pp. 1-8.

OECD Health Data (2018), "Spending on health: latest trends", available at: www.oecd.org/health/health-systems/ Health-Spending-Latest-Trends-Brief.pdf

OECD Health Data (2019), "Health spending", available at: https://data.oecd.org/healthres/health-spending.htm

Papalexi, M. (2017), "An investigation into the aspects of innovation within the downstream domain of the pharmaceutical supply chain", $\mathrm{PhD}$ thesis. University of Huddersfield.

Papalexi, M., Bamford, D. and Dehe, B. (2015), “A case study of Kanban implementation within the pharmaceutical supply chain", International fournal of Logistics Research and Applications, Vol. 19 No. 4, pp. 239-255.

Pappa, E. and Niakas, D. (2006), "Assessment of health care needs and utilization in a mixed public-private system: the case of the Athens area", BMC Health Services Research, Vol. 6 No. 1, p. 146.

Pereira, R.C., Christopher, M. and Lago Da Silva, A. (2014), "Achieving supply chain resilience: the role of procurement", Supply Chain Management: An International fournal, Vol. 19 Nos 5/6, pp. 626-642.

Petty, N., Thomson, O. and Stew, G. (2012), "Ready for a paradigm shift? Part 2: introducing qualitative research methodologies and methods", Manual Therapy, Vol. 17 No. 5, pp. 378-384.

Pohjosenperä, T., Kekkonen, P., Pekkarinen, S. and Juga, J. (2018), "Service modularity in managing healthcare logistics", The International Fournal of Logistics Management, Vol. 30 No. 1, pp. 174-194.

Radnor, Z.J., Holweg, M. and Waring, J. (2012), "Lean in healthcare: the unfilled promise?", Social Science \& Medicine, Vol. 74 No. 3, pp. 364-371.

Rosano, A., Lauria, L., Viola, G., Burgio, A., De Belvis, A.G. and Ricciardi, W. (2011), "Hospitalization for ambulatory care sensitive conditions and the role of primary care", Italian Fournal of Public Health, Vol. 8 No. 1, pp. 77-88.

Saldana, J. (2013), The Coding Manual for Qualitative Researchers, Sage Publications, Los Angeles.

Sandø, A.D., Aanes, S.G., Slordal, L. and Spigset, O. (2010), "Routines for first prescription or oral contraceptives", Tidsskrift for Den Norske Legeforening, Vol. 130 No. 23, pp. 2344-2348.

Saunders, M., Lewis, P. and Thornhill, A. (2015), Research Methods for Business Students, 7th ed., Prentice Hall, Harlow.

Schadewaldt, V., McInnes, E., Hiller, J.E. and Gardner, A. (2014), "Investigating characteristics of collaboration between nurse practitioners and medical practitioners in primary health care: a mixed methods multiple case study protocol", fournal of Advanced Nursing, Vol. 70 No. 5, pp. 1184-1193.

Scheller, E.S. and Smeltzer, L.R. (2006), Strategic Management of the Health Care Supply Chain, 1st ed., Wiley, San Francisco, CA.

Sen, M., Chaudhury, A., Singh, R., John, J. and Ramachandran, R. (2013), "Multi-scale flow sheet simulation of an integrated 
continuous purification - downstream pharmaceutical manufacturing process", International fournal of Pharmaceutics, Vol. 445 Nos 1/2, pp. 29-38.

Singh, C.D., Singh, R. and Singh, S. (2013), "Application of lean and JIT principles in supply chain management", International fournal of Management Research and Business Strategy, Vol. 2 No. 1, pp. 2319-2345.

Souliotis, K. and Lionis, C. (2005), "Creating an integrated health care system in Greece: a primary care perspective", Fournal of Medical Systems, Vol. 29 No. 2, pp. 187-196.

Statista (2018), "Global spending on medicines from 2010 to 2022", available at: www.statista.com/statistics/280572/ medicine-spending-worldwide

Theodorou, M., Tsiantou, V., Pavlakis, A., Maniadakis, N., Fragoulakis, V., Pavi, E. and Kyriopoulos, J. (2009), "Factors influencing prescribing behaviour of physicians in Greece and Cyprus: results from a questionnaire based survey", BMC Health Services Research, Vol. 9 No. 1, p. 150.

Tongco, M. (2007), "Purposive sampling as a tool for informant selection", Ethnobotany Research and Applications, Vol. 5 No. 2, pp. 147-158.

Tukamuhabwa, B., Stevenson, M. and Busby, J. (2017), "Supply chain resilience in a developing country context: a case study on the interconnectedness of threats, strategies and outcomes", Supply Chain Management: An International fournal, Vol. 22 No. 6, pp. 486-505.

Uthayakumar, R. and Priyan, S. (2013), "Pharmaceutical supply chain and inventory management strategies: optimization for a pharmaceutical company and a hospital", Operations Research for Health Care, Vol. 2 No. 3, pp. 52-64.

Vaismoradi, M., Jones, J., Turunen, H. and Snelgrove, S. (2016), "Theme development in qualitative content analysis and thematic analysis", Fournal of Nursing Education and Practice, Vol. 6 No. 5.

Volland, J., FFgener, A., Schoenfelder, J. and Brunner, J. (2017), "Material logistics in hospitals: a literature review", Omega, Vol. 69, pp. 82-101.

Wang, Z., Zhang, X., Huang, Y. and Wang, H. (2015), "Comprehensive evaluation of pharmaceuticals and personal care products (PPCPs) in typical highly urbanized regions across China”, Environmental Pollution, Vol. 204, pp. 223-232.

Weingart, S.N., Mattsson, T. and Zhu, J. (2012), "Improving electronic oral chemotherapy prescription: can we build a safer system?", Fournal of Oncology Pharmacy Practice, Vol. 8 No. 6, pp. 168-173.

Wilson, T. and Holt, T. (2001), "Complexity and clinical care”, BMF, Vol. 323 No. 7314, pp. 685-688.

Xie, Y. and Breen, L. (2012), "Greening community pharmaceutical supply chain in UK: a cross boundary approach", Supply Chain Management: An International Fournal, Vol. 17 No. 1, pp. 40-53.

Xie, Y. and Breen, L. (2014), "Who cares wins? A comparative analysis of household waste medicines and batteries reverse logistics systems", Supply Chain Management: An International fournal, Vol. 19 No. 4, pp. 455-474.

Zacharia, Z., Sanders, N. and Fugate, B. (2014), "Evolving functional perspectives within supply chain management", fournal of Supply Chain Management, Vol. 50 No. 1, pp. 73-88.
Zahiri, B., Jula, P. and Tavakkoli-Moghaddam, R. (2018), "Design of a pharmaceutical supply chain network under uncertainty considering perishability and substitutability of products", Information Sciences, Vol. 423, pp. 257-283.

\section{Further reading}

Laínez, J., Schaefer, E. and Reklaitis, G. (2012), “Challenges and opportunities in enterprise-wide optimization in the pharmaceutical industry", Computers \& Chemical Engineering, Vol. 47, pp. 19-28.

\section{Appendix 1. Interview questions}

\section{Part 1 - General questions about the study phe- nomenon and the role of the interviewee with in the pharmaceutical supply chain}

The role of the interviewee with in the PSC

- What is your role within the PSC?

- How many years of experience do you have?

- What is your education level?

- To what extent the delivery system that you have been involved is effective?

- What type of improvements is required for the delivery system to operate effectively?

SC

- Who are the key players/SC partners in the pharmaceutical industry?

- What is their relationship into PSC?

- What is the role of each of the stakeholders in PSC?

- Is there any specific guidance that needs to be followed while conducting the delivery process?

- How is the communication between them achieved?
Material flow
Financial flow
Information flow
Demand flow

- Who generates the demand?

Materials-suppliers

- How do you select the medicines that you are going to use?

- How many categories of products are there?

- How often do you collect the products?

- Which is the inventory policy/safe storage/stock level/ demand management, forecasts?

- Do you operate an ERP system or another to manage your inventory?

- Do you cooperate with steady suppliers? Why?

\section{Part 2 - the factors preventing an effective deliv- ery process}

- What are the problems, which have been occurred/ observed in PSC? Can they be scaled as follows? 


\section{Part 3 - Improvement approaches}

Materials

Resources

Cost

Knowledge

Quality

- How do you cover the urgent issues?

- To what extend the existing regulations create a delay?
- Are there any improvement approaches been applied within the delivery process that you are involved?

- In your point of view what was the motivation for using them?

- Who is driving those approaches?

- What are the benefits of their application?

- Are there any factors that prevent the implementation of any innovative approaches? 


\section{Appendix 2}

Table A1 Interviewee details

\begin{tabular}{|c|c|c|c|c|c|c|}
\hline$\#$ & Reference & Gender & Position & $\begin{array}{l}\text { Working } \\
\text { experience }\end{array}$ & Educational level & $\begin{array}{l}\text { System's } \\
\text { innovativeness }\end{array}$ \\
\hline 1 & 6/UK & $\mathrm{M}$ & Acting chief pharmacist & 5 Yrs & Bachelor's degree & Disagree \\
\hline 2 & 7/UK & $\mathrm{F}$ & Chief pharmacy technician & 9 Yrs & Bachelor's degree & Neutral \\
\hline 3 & 8/UK & M & Lead pharmacist & 11 Yrs & Bachelor's degree & Neutral \\
\hline 4 & 9/UK & $\mathrm{F}$ & Community pharmacist & 7 Yrs & Bachelor's degree & Disagree \\
\hline 5 & 10/UK & $\mathrm{F}$ & Chief pharmacist & 9 Yrs & Bachelor's degree & Agree \\
\hline 6 & 4/UK & M & Procurement and homecare manager & 7 Yrs & Postgraduate degree & Agree \\
\hline 7 & $5 /$ UK & $\mathrm{F}$ & Chief pharmacy technician & 4 Yrs & Bachelor's degree & Agree \\
\hline 8 & $11 / \mathrm{UK}$ & M & Lead pharmacist & 8 Yrs & Bachelor's degree & Neutral \\
\hline 9 & $12 / \mathrm{UK}$ & $\mathrm{F}$ & Reader advancing clinical practice & 14 Yrs & Postgraduate degree & Neutral \\
\hline 10 & 13/UK & $\mathrm{F}$ & Senior lecturer, nursing and health studies & 12 Yrs & Postgraduate degree & Neutral \\
\hline 11 & $14 / G r$ & $\mathrm{M}$ & Hospital pharmacist & 15 Yrs & Bachelor's degree & Disagree \\
\hline 12 & $15 / \mathrm{Gr}$ & M & Hospital pharmacist & 13 Yrs & Bachelor's degree & Disagree \\
\hline 13 & $16 / \mathrm{Gr}$ & $\mathrm{F}$ & Community pharmacist & 5 Yrs & Bachelor's degree & Neutral \\
\hline 14 & $18 / \mathrm{Gr}$ & $\mathrm{F}$ & Hospital pharmacist & 15 Yrs & Postgraduate degree & Disagree \\
\hline 15 & $17 / G r$ & $\mathrm{~F}$ & Community pharmacist & 22 Yrs & Bachelor's degree & Neutral \\
\hline 16 & $19 / G r$ & $\mathrm{M}$ & Community pharmacist & 6 Yrs & Bachelor's degree & Agree \\
\hline 17 & 20/UK & $\mathrm{M}$ & Community pharmacist & 7 Yrs & Bachelor's degree & Neutral \\
\hline 18 & $21 / U K$ & $\mathrm{~F}$ & Community pharmacist & 4 Yrs & Bachelor's degree & Neutral \\
\hline 19 & $22 / U K$ & $M$ & Community pharmacist & 5 Yrs & Bachelor's degree & Disagree \\
\hline 20 & $1 / \mathrm{UK}$ & $\mathrm{F}$ & Lead pharmacist & 8 Yrs & Postgraduate degree & Agree \\
\hline 21 & 2/UK & $M$ & Chief pharmacist & 11 Yrs & Bachelor's degree & Neutral \\
\hline 22 & 23/UK & $M$ & Community pharmacist & 4 Yrs & Bachelor's degree & Neutral \\
\hline
\end{tabular}

\section{Corresponding author}

Marina Papalexi can be contacted at: M.Papalexi@mmu.ac.

uk

For instructions on how to order reprints of this article, please visit our website:

www.emeraldgrouppublishing.com/licensing/reprints.htm

Or contact us for further details: permissions@emeraldinsight.com 